(2) Instances in which any one of the above peculiarities has appeared in the broods of different parents. In replying to this question, it will be hardly worth while to record the sudden appearance of either albinism or melanism, as both are well known to be of frequent occurrence.

Note. - The question is not asked now, whether such peculiarities, or "sports," may be accounted for by atavism or other hypothetical cause.

(3) Instances in which any of these peculiarly characterised individuals have transmitted their peculiarities, hereditarily, to one or more generations. Especial mention should be made whether the peculiarity was in any case transmitted in all its original intensity, and numerical data would be particularly acceptable, that showed the frequency of its transmission $(a)$ in an undiluted form, $(b)$ in one that was more or less diluted, and $(c)$ of its non-transmission in any perceptible degree. ${ }^{1}$

It is impossible to exp'ain to a general meeting the precise way in which the desired facts would be utilised. An explanation that would be sufficiently brief for the purpose could not be rendered intelligible except to those few who are already familiar with the evidence, and the technical treatment of it by which the law of Regression is established, and with the con sequences and requirements of that law. Regressiveness and stability are contrasted conditions, and neither of them can be fully understood apart from the other.

I may as well take this opportunity of appending a list of my various memoirs on these subjects. They appeared from time to time in various forms as the inquiry progressed and as suitable openings occurred for writing or speaking. The more important of these are Nos. 1,3 , part of 6,7 , and 8 in the following list. Nos. 1 to 5 refer to regression only.

List of Memoirs, By Mr. F, Galton, on Regression AND ORGanic STABILITY.

(I) Typical Laws of Heredity. Fournal of the Royal Institution, 1877. (This was the first statement of the law of Regression, as founded on a series of experiments with sweet peas.)

(2) Presidential Address, Anthropological Section of the British Association, I885. (Here the law of Regression was confirmed by anthropological observations.)

(3) Regression towards Mediocrity in Family Stature. Fournal of the Anthropological Institute, 1885. (A revised and illustrated reprint of No. 2.)

(4) Family Likeness in Stature. Proc. Roy. Soc., 1886.

(5) Family Likeness in Eye Colour. Proc. Roy. Soc., 1886.

(6) Natural Inheritance. (Macmillan and Co., 1889.) (This volume summarises the results of previous work.)

(7) Patterns in Thumb and Finger Marks ... and th Resemblance of their Classes to Ordinary Genera. Phil. Trans. Roy. Soc., I891.

(8) Discontinuity in Evolution. Mind, I894. (An article on Mr. Bateson's work.)

\section{A NEW DETERMINATION OF THE OHM.} \section{A IRESH determination of the value of the ohm in} A absolute measure has been made by F. Himsted (Wiedemann's Annalen, liv. p. 305). The method employed is that which the author had used in a previous determination, and consists of passing through a galvanometer all the make or break currents induced in a secondary coil when the current in a long primary helix is interrupted a known number of times per second. A known fraction of the primary current is then passed through the same galvanometer. The primary helix in these experiments consists of a single layer of uncovered copper wire, wound, by means of a screw-cutting lathe, in a regular spiral on a glass cylinder. The turns of wire are held in their place, and the insulation improved, by being coated with shellac. As the mean of a number of determinations, the author obtains the value 106.28 $\mathrm{cm}$. as the length of the column of mercury at $0^{\circ} \mathrm{C}$., having a cross section of one square millimetre, which has the resistance of $10^{9}$ C.G.S. units. In connection with the above-described experiments, the author has been led to measure some coefficients of self-induction, using for this purpose a modification of the Rayleigh-Maxwell method. The great difficulty in measuring a coefficient of self-induction by this method is

1 Written communications should be addressed to F. Galton, 42, Rutland Gate, London, S.W.

$$
\text { NO. } 1328 \text {, VOL } 5 \mathrm{I}]
$$

that, in order to get a throw of sufficient magnitude to be accurately measured, it is necessary to employ a somewhat strong current. The result is that the temperature of the coil, the selfinduction of which is being measured, rises rapidly, and thus the balance of the Wheatstone's bridge for steady currents is upset. Herr Himstedt gets over this difficulty by using the commutator, which he employs in his determination of the ohm, to break the battery circuit a known number of times per second, and to cut the galvanometer out of circuit while either the $m i k e$ or break is taking place. In this way a steady deflection is obtained of sufficient magnitude to be readily measured, even when the current employed is between o.001 and 0.002 amperes. The above method only differs from that employed by Profs. Ayrton and Perry in their secohm-meter, in that the author takes two separate readings, one with the bridge balanced for steady currents, the other when the commutator is working, instead of bringing the galvanometer deflector to zero by upsetting the steady current balance.

\section{THE SMITHSONIAN INSTITUTION REPORT} FOR 1894 .

MR. S. P. LANGLEY'S report of the operations of the Smithsonian Institution for the year ending June 30, I 894 , has just reached this country, and it furnishes interesting reading on a number of points relating to the U.S. National Museum, the Bureau of Ethnology, the Bureau of International Exchanges, the National Zoological Park, and the Astrophysical Observatory.

The total permanent funds of the Institution are now 911,000 dollars, and interest at the rate of 6 per cent. per annum is allowed upon this by the Treasury, the interest alone being used in carrying out the aims of the Institution. The total receipts during the fiscal year covered by the Report amounted to 69,967 dollars, and the entire expenditure, including a sum of eight thousand dollars added to the permanent fund, was $67,46 \mathrm{I}$ dollars. The Institution also disbursed the Treasury grants of 14,500 dollars for International Exchanges ; 40,000 dollars for North American Ethnology; 154,000 dollars for the U.S. National Museum ; 50,000 dollars for the National Zoological Park; and 9000 dollars for the Astro.Physical Observatory.

It appears to be an essential portion of the original scheme of the government of the Institution that its secretary should be expected to advance knowledge, whether in letters or in science, by personal research ; but the increasing demands of time for labours of administration has greatly limited the possibility of doing this. Mr. Langley has, however, found time to continue his researches upon the solar spectrum (see NATURE, November $1, \mathbf{8 9 4 )}$ ). This work, carried on in the Astro-Physical Observatory, is certainly of more than common importance. His investigations upon aerodynamics have also been continued intermittently. They are not complete, but they appear to point to conclusions of general and unusual interest.

A widespread interest seems to have been awakened in the Hodgkins competition, with reference to investigations appertaining to the nature and properises of atmospheric air. A letter printed in NATURE of June 21,1894 , announced that the time within which papers might be submitted was extended to the end of last year. The Report informs us that, up to June 30 , 1894, 250 memoirs, printed and manuscript, had been received in connection with the competition, representing correspondents in the United States, Mexico, England, Scotland, Norway, Denmark, Russia (including Finland), France, Belgium, Germany, Austria.Hungary, Servia, Italy, and Britısh India.

A few grants have been made from the Hodgkins Fund, in aid of certain important researches. In this connection we notice that Prof. E. W. Morley's work on the determinations of the density of oxygen and hydrogen, aided by special ap. paratus provided by the Institution, is approaching completion.

The investigations undertaken by Dr. J. S. Billings and Dr. S. Weir Mitchell into the nature of the peculiar substances of organic origin contained in the air expired by human beings, has been continued under a grant from the Hodgkins Fund, and also the researches by Dr. O. Lummer and Dr. E. Pringsheim, of Berlin University, on the determination of an exact measure of the cooling of gases while expanding, with a view to revising the value of that most important constant which is technically termed the "gamma" function.

$\mathrm{Mr}$. Langlev refers again to the unsatisfactory condition of the National Museum. The collections have increased so 
greatly that unless additional space is provided for their proper administration and exhibition, the efficiency of the Museum will be greatly impaired; but though the collections are growing rapidly in certain directions, they are not increasing as symmetrically and consistently as is manifestly desirable-a very common cause of complaint. A defect which calls for instant attention, however, relates to the most undesirable and dangerous storage of collections in woodin sheds near the Smiths nian building, and in the basement of the building itself, where large alcoholic collections in bottles containing, in the bulk, many thousands of gallons of alcohol, have been put a way, as space cannot be found for the specimens in the Museum. It appears that a fire communicated to these rooms would sweep through the entire length of the building, and although the building itself is fireproof as against any ordinary danger, it may well be doubted whelher any of the collections therein exhibited can be regarded as safe, if the rooms immediately below should be exposed to so peculiarly severe a conflagration as would be caused by the ignition of these large quantities of inflammable material. Such a calamity would affect the whole scientific world, and we trust that the appeal for a change of the present condition of affairs will not be disregarded.

The investigations relating to the ethnology of the American Indians were carried forward during the year, under the efficient control of Major J. W. Powell, the director, aided by Mr. W. J. McGee, ethnologist in charge, as executive officers. These researches of the Bureau of American Ethnology embrace the subjects of archæology, descriptive ethnology, sociology, pictography and sign language, linguis ics, mythology, psychology, and bibliography, and the results obtained during the year have never been exceeded in value.

The Smithsonian Exchange Service was inaugurated nearly half a century ago, with the object of carrying out one of the purposes of the founder of the Institution in the diffusion of that knowledge which the Institution itself helped to create. For this purpose it established correspondence with scientific men all over the world, until there is no civilised country or people, however remote, upon the surface of our planet, so far as is known, where the Institution is not thus represented. These corre-pondents have grown in numbers until at the present time those external to the United States alone number nearly 17,000 . More than one hundred tons of books passed through the exchange office during the fiscal year r $893-94$.

It was only five years ago since an appropriation was made for the National Zoological Park at Washington. The park has an area of nearly 167 acres, but there are as yet only four permanent buildings, while the animals number $5 \mathrm{ro}$, of which 200 are of the larger size. Comparing this with similar establish. ments at other capitals, it is noted that the Gardens of our Zoological Society cover about 36 acres, are crowded with buildings, and that the magnificent collection of animals, some 2300 in number, is housed in a fairly comfortable manner. In Paris the portion of the Jardin des Plantes assigned to animals is a plat of ground some 17 acres in extent, crowded with 900 animals. In Berlin the portion of the Thiergarten appropriated for animals occupies about 60 acres. Fifteen hundred animals are accommodated and, necessarily, much overcrowded. In the United States the principal collections are in Philadelphia, where the grounds occupy about 40 acres, and the collection comprises 881 animals; in Cincinnati, where 36 acres are occupied with about 800 animals ; and in New York, where the city maintains about 700 animals in Central Park, occupying an area of approximately ro acres. In none of these collections are the grounds of sufficient size to give any extensive range for the animals.

Appended to Mr. Langley's general account of the affairs of the Institution and of its bureaus, are the detailed and statistical reports from the officers in charge of the different branches of work. The whole shows how very great and valuable is the work done in the United States "for the increase and diffusion of knowledge among men."

\section{UNIVERSITY AND EDUCATIONAL} INTELLIGENCE.

Prof. C. S. Sherrington, F.R.S., has been appointed to the George Holt Chair of Physiology in University College, Liverpool.

NO. I 328 , VOL. 5 I]
Dr. A. W. Crossley, Berkeley Fellow, and Demonstrator of Organic Chemistry, in the Onens College, Manchester, has been elected Demonstrator of Chemistry in the Medical School of St. Thomas's Hospital, in succession to Dr. W. H. Ince, who has been appointed Government Chemist at Trinidad.

Sir Dinshaw Manockjee Petit, Bart., has, through the Principal, Mr. S. Cooke, offered to the Indian Government the sum of 5000 rupees towards the cost of providing residential quarters for Parsee students attending the College of Science at Poona.

THE Governors of Colfe's Foundation have selected Mr. F. W. Lucas to be Head Master of Colfe's Grammar School, Lewisham, from September next. Mr. Lucas is at present Head Master of Hipperholme Grammar School, Yorks, and was formerly Senior Assistant and Science Master at Roan School, Greenwich.

WE learn from the Lancet, that in accordance with the will of the late Dr. G. X. Heath, Professor of Surgery in the University of Durham, and President of the University of Durham College of Medicine, the trustees of the Heath Scholarship, Prof. W. C. Arnison and Mr. Frederick Page, will award and pay to the writer of the best essay on Surgical Diseases of the Jaws the sum of $£ 200$. All graduates in medicine or in surgery of the University of Durham are eligible to compete for this prize. The essay must be typewritten or printed, and delivered to the trustees not later than March $3 \mathbf{I},{ }_{1896}$. The essay, together with any specimens, drawings, casts, microscopical preparations, or other means of illustration accompanying it, will become the property of the College of Medicine, Newcastle-upon-Tyne, but by permission the essay may be printed for general circulation by the Heath Sctrslar. Mr. Stephen Scott, of Harrogate, has generously presented to the College of Medicine the sum of $£ \mathrm{roOo}$, which has been devoted, in accordance with Mr. Scott's wish, to founding a scholarship to promote the study of hernia and allied subjects. Any graduate in medicine or surgery of the University of Durham, or any sludent of the University of Durham College of Medicine is eligible to compete for the scholarship, provided that such student shall have had at least one academical year in attendance at the College, and that in any case his age does not exceed thirty years at the time when the essay is sent in. The competition takes place every year. Essays for this year's competition must be sent not later than July 3I, I895, to Prof. Arnison, University of Durham College of Medicine, Newcastle-upon-Tyne.

ON Friday last, Mr. Acland received a deputation at the Education Office, from the representatives of the Association of Head Masters, respecting the recent regulations which have been issued by the Science and Art Department with reference to organised science schools. After hearing the views of the deputation, Mr. Acland, in reply, said it was not desired to make an upheaval of the arrangements for these schools, but to juin together in improving the method and the system on which the teaching was carried on. They were all agreed that to lessen too frequent examination, and to introduce the element of inspection, if reasonably carried on in a friendly spirit, would be of great value to these schools. One of the objects of the Department had been to make it clear that, besides the teaching of science, which was the primary object of these schools, they also desired fully to recognise the element of literature and the teaching of special subjects. In order to meet a point which had been raised, as 10 the change from the old system of organised science schools to the new, the closing words of the syllabus would be :--" Reasonable latitude will be allowed for two years in any departures which may be made from the prescribed course while the changes from the present to the new system are being brought about." Taking these words, together with the $n$ ords in the earlier part of the syllabus, as to reasonable latitude being allowed to teachers as to the nature of the course which they might pursue, provided that the insuluction was sound, satisfactory in amount, and combined with proper practical work, it would be seen that the Department had no intention of being too despotic, and that if really good and reasonable work was done under some more elastic system, these organised science schools would be found of even more benefit in the future than they had been in the past. 